\title{
MENTAL HEALTH-RELATED STIGMA AND DISCRIMINATION IN GHANA: EXPERIENCE OF PATIENTS AND THEIR CAREGIVERS
}

\author{
P. E. TAWIAH ${ }^{1}$, P. B. ADONGO ${ }^{2}$ and M. AIKINS ${ }^{2}$ \\ ${ }^{1}$ Mental Health Department, Volta Regional Health Directorate, Ghana Health Service, Ho, Ghana ${ }^{2}$ School of \\ Public Health, College of Health Sciences, University of Ghana, Accra, Ghana.
}

DOI: $h t t p: / / d x . d o i . o r g / 10.4314 / g m j . v 49 i 1.6$

Corresponding Author: Dr. Moses Aikins

Email: maikins57@yahoo.com

Conflict of Interest: None declared

\section{SUMMARY}

Background: Mental health is now attracting increased public health attention from health professionals, policy makers and the general population. However, stigma and discrimination usually have enormous negative impact on the patients and their families. This study reports on stigma and discrimination faced by mental health patients and their caregivers in a suburban area of Ghana and the coping strategies used.

Method: This is a cross-sectional exploratory study which used both quantitative and qualitative approaches. Two hundred and seventy seven mental health patients were purposively interviewed. Focus group discussions were held with caregivers and in-depth interviews were held with mental health professionals. The quantitative data were analyzed using SPSS and Microsoft Excel ${ }^{\circledR}$ whilst the qualitative data were coded and manually analyzed thematically.

Results: Mental disorder cuts across all age, sex, education, ethnicity, employment, and marital status. More females were stigmatized than males at the work/employment and educational levels. Various forms of stigma were observed at the economic, psychological and social levels, whilst for discrimination it was only observed at the economic and social levels. Caregivers were also stigmatized and discriminated. The coping strategies adopted by the mental patients and their caregivers were also economic, psychological and social in nature.

Conclusion: Mental health patients and their families suffer from stigma and discrimination from the individual, family, work, employment, education to the health level. Thus, community level policy on mental health care needs to be developed and implemented. Furthermore mental health education needs to be intensified at the community level.

Keywords: stigma, discrimination, mental health, caregivers, coping strategies, Ghana

\section{INTRODUCTION}

In recent years, mental health has attracted increased public health attention. This is as a result of the enormous negative impact stigma and discrimination usually has on the patients and their families. This impact could be felt at home, the workplace and the community. ${ }^{1}$ The modern understanding of disease stigma owes much to Goffman, who suggested that people who possess a characteristic defined as socially undesirable mental disorder in this case acquire a 'spoiled identity' which then leads to social devaluation and discrimination. $^{2}$

Stigma is classified into felt or perceived stigma and enacted stigma. Felt stigma refers "to real or imagined fear of societal attitudes and potential discrimination arising from a particular undesirable attribute, disease (such as mental disorders), or association with a particular group". ${ }^{3}$ Enacted stigma, on the other hand, refers "to the real experience of discrimination". ${ }^{3}$ This takes the form of discrimination in job placement or loss of job as a result of disclosure of mental health status, health benefits, or social ostracism.

World Health Organization defines mental health as "a state of well-being in which the individual realizes his or her own abilities, can cope with the normal stresses of life, can work productively and fruitfully, and is able to contribute to his or her community". ${ }^{4}$ From the definition, mental disorder therefore is viewed as any condition that makes it difficult for an individual to cope with normal stresses of life, or state of mental and social disequilibrium. Stigma and discrimination for the mentally ill individual is becoming problematic globally.

Stigma leaves mental patients in state of grief. It also prevents them from seeking for help and induces a feeling of helplessness and hopelessness. It impedes investment in necessary mental health services and research as governments and funding agencies ignore this most important area of population health. ${ }^{5}$ 
Stigma contributes to what a WHO fact sheet identified as the hidden burden of mental illness ${ }^{6}$, and it constitutes a hidden burden for other stigmatized conditions as well. It has also been shown that stigma and labeling may affect the course of recovery. ${ }^{7}$ It is estimated that $25 \%$ of the general population suffers from various forms of mental disorder.

Mental disorder accounts for at least 160 million lost years of healthy life, of which about $30 \%$ could be averted with existing intervention. ${ }^{8}$ Stigma and discrimination make it difficult for treated mental disorder patients to reintegrate into the community. People, who lived with psychiatric stigma and its consequences, often experience suffering that is devastating, and lifelimiting. ${ }^{9}$ Stigma and discrimination prevent people with mental illness from obtaining the basic family and community care that others enjoy. ${ }^{10}$ They impede social integration, interfere with performance of social roles, diminish quality of life, and prevent timely access to treatment, effectively creating a vicious cycle of social disadvantage and disability. ${ }^{11}$

Furthermore, some families abandon mental patients at the psychiatric hospital resulting in congestion at the hospital. ${ }^{12}$ Moreover, other reports indicate that stigma and discrimination were the key reasons for this behaviour. ${ }^{12}$ Contemporary studies on stigma and discrimination are mainly focus on communicable diseases such as HIV/AIDs, TB and buruli ulcer. ${ }^{5}$ This study aims to provide more documentary evidence on the types of mental health stigma and discrimination, and also some understanding of the nature of challenges, coping and support strategies used by patients and their caregivers. Some lessons can be drawn from these to inform programme and policy formulation at the community levels.

\section{METHODS}

\section{Study area}

Ho Municipality is one of the 18 administrative districts in the Volta region. Ho town doubles as the $\mathrm{Mu}-$ nicipal and the Regional Capital of the Volta Region. The Municipality has four (4) sub municipalities namely: Abutia,Tsito, Kpedze-Vane, Ho-Shia and it comprises 474 communities with an estimated population of $225,026 .^{13}$

The Ho Municipality has 2 health facilities that render mental health services. The Ho Municipal Hospital offers outpatient mental health service whilst Volta Regional Hospital provides both outpatients and inpatient mental health services. There is only 1 psychiatrist and 4 mental health nurses in the Municipality. ${ }^{14}$

\section{Patients}

The study was a cross-sectional exploratory one. Using a simple random sampling approach (i.e., $\left(\mathrm{z}_{\alpha / 2}^{2} \mathrm{x} p q\right) / \mathrm{d}^{2}$ : where $z$ is the confidence level $(95 \%)$, with an assumed $50 \%$ of the population at risk of mental illness and a $5 \%$ degree of error. A total sample of 385 was obtained. The study was able to recruit 277 (i.e., $72 \%$ response rate). At the time of the study a total of 848 mental patients were registered with mental health clinics in the Ho Municipality: 640 in the Volta Regional Hospital and 208 in Ho Municipal Hospital. Based on these patient registrations, the sample selection was proportionally allocated. Thus 204 patients were recruited from Volta Regional Hospital and 73 patients from the Ho Municipal Hospital. Patients were diagnosed using International Classification of Diseases (ICD-10 Version: 2010), Chapter 5, Mental and behavioural disorders (F00 - F99) by mental health nurses and the psychiatrist in the hospitals. The some of the disorders were schizophrenia, schizotypal and delusional disorders, depression and mood (affective) disorders, mental disorders due to alcohol use, mental disorders due to cannabis use, mental disorders due to psychoactive substance use, etc.

\section{Selection of patients and caregivers:}

Using the patient registers, the patient numbers were written on pieces of papers and random sampling approach of lottery was used to select the patients for each hospital. On the interview day, the main caregiver of the selected patient was identified and automatically recruited as part of the study. All the interviews were carried out at the premises of the hospitals.

\section{Data}

Three main data collection tools were used namely structured questionnaire, focus group discussion and in-depth interview guides. The tools were all designed in English and translated into local languages (i.e., Ewe and Akan) and back translated into English. The questionnaire and guides were pre-tested on 10 patients in the Ketu South District Hospital's Mental Health Unit. Two trained research assistants administered the questionnaire in a face-to-face interview.

The structured questionnaire had the following main sections: demographic data, history of disease condition, forms of stigma and discrimination (i.e., at individual, work, employment and education, family, health system levels), and lastly, challenges, coping and support strategies each of which covered economic, psychological and social issues. 
A five-point Likert scale ranging from "strongly agree" to "strongly disagree" was used to rate the responses. Prior to the interview, informed consent was either obtained from subjects or their caregivers.

Two trained researcher assistants carried out the interviews. The focus group discussions (FGDs) and indepth interviews (IDIs) were tape recorded with permission and transcribed after the interviews. Guides were used to facilitate the FGDs with the caregivers and the community members and the IDIs. Four FGDs were held with caregivers, health care providers, household family members of patients and community members. In-depth interviews were held with four community mental health practitioners and a psychiatrist.

\section{Analyses}

The quantitative data was cleaned and entered into SPSS Version 16 and analysed descriptively. This was then summarized into frequencies, tables and graphs using Microsoft Excel ${ }^{\circledR}$. Means were calculated and used to draw the radar chart for the Likert scale responses to the four main stigma and discrimination levels: individual, work, employment and education, family and health system levels. The FGD and IDI were coded using thematic coding and transcribed. This was then presented in the form of narrative and quoting verbatim to complement the quantitative data.

\section{Study Limitations}

The main limitations were: (a) timing or the period of the study as some of the patients and caregivers who might be experiencing stigma and discrimination might not have reported at the mental health clinic during the study period, (b) FGDs in the two communities for patients' caregivers may have influenced their responses.

\section{Ethical Consideration}

Ethical approval for the study was obtained from the Ghana Health Service Ethical Review Committee. Permissions were also sought from the Regional Directorate of Health Services, Managements of Volta Regional and Ho Municipal Hospitals prior to data collection. Patient and their caregivers were also assured of the privacy, confidentiality, data safety and appropriate data usage by using anonyms, codes and pseudonyms during data analyses and collation. There were no known risks of using the data, and benefits of using the collected data were immense to provide evidence based information on mental health-related stigma and discriminations. Furthermore, there was no conflict of interest.

\section{RESULTS}

\section{Background characteristics of patients}

Table 1 shows the background characteristics of the patient. Slightly over half of the patients (about 55\%) were $35 y e a r s$ and above. About $62 \%$ of the patients were females and 50\% were not married and also about $15 \%$ were divorced. Thirty-three percent (91) had primary education and $11 \%$ tertiary education. Twentythree percent (63) were farmers and about 6\% were unemployed. Further analysis shows that about $93 \%$ of the patients practiced the Christian faith.

\section{Table 1: Background characteristics of respondents}

\begin{tabular}{|l|l|}
\hline Characteristics & Number (\%) \\
\hline Age: & \\
$<20$ years & $35(13)$ \\
$21-34$ years & $90(32)$ \\
$>35$ years & $152(55)$ \\
Sex: & \\
Male & $105(38)$ \\
Female & $172(62)$ \\
Marital Status: & \\
Married & $77(28)$ \\
Never Married & $139(50)$ \\
Divorced & $39(14)$ \\
Widowed & $11(4)$ \\
Non-Responses & $11(4)$ \\
Educational Level: & \\
None & $40(14)$ \\
Primary & $91(33)$ \\
MSLC/JHS & $75(27)$ \\
Secondary & $35(13)$ \\
Tertiary & $30(11)$ \\
Non-Response & $6(2)$ \\
Occupation: & \\
Farming & $63(23)$ \\
Trading & $58(21)$ \\
Civil Servant & $27(10)$ \\
Unemployed & $18(6)$ \\
Others & $108(39)$ \\
Non- Response & $3(1)$ \\
\hline Total & $277(100)$ \\
\hline
\end{tabular}

Causes, duration and preferred treatment of mental disorders

Table 2 shows the reported causes, and preferred treatment of mental disorders. The main reported cause of mental disorder was biological (45\%) and about $32 \%$ also reported that it was due to spiritual causes and curses. The duration of mental disorders among the patients ranges from less than 1 year to 15 years and over. About $60 \%$ of cases were less than 9 years, of which $36 \%$ were $1-4$ years modal duration. Finally, the preferred treatment of mental disorder was biomedical (79\%) and faith-based (18\%). As a 48-year-old woman caregiver narrated:

"When people know in this town that one is having mental disorder, they point out accusing fingers to the person, claiming it is as a result of curse or punishment from their gods or misdeeds, so is better not to disclose 
your status. So prayer camps and traditional healers are our help, even if it is a curse or punishment they will help you. Mental illness is "madness" which means the person with queer, bizarre, strange behaviour and in tattered and dirty clothing or naked, wondering and roaming around aimlessly, picking from the ground, eating garbage, it is a curse, punishment from gods, is better you visit a prayer camp than hospital people will shun your company in the community”.

Table 2 Causes, duration and preferred treatment of mental disorders

\begin{tabular}{|c|c|}
\hline Items & Number (\%) \\
\hline \multicolumn{2}{|l|}{ Causes of mental disorders: } \\
\hline Spiritual/curse & $87(32)$ \\
\hline Biological $^{*}$ & $123(45)$ \\
\hline Don't know & $61(23)$ \\
\hline Total & $271(100)$ \\
\hline \multicolumn{2}{|l|}{ Duration of mental disorders: } \\
\hline$<1$ year & $33(12)$ \\
\hline $1-4$ years & $100(36)$ \\
\hline $5-9$ years & $33(12)$ \\
\hline $10-14$ years & $55(20)$ \\
\hline$>15$ years & $53(19)$ \\
\hline Total & $274(99)$ \\
\hline \multicolumn{2}{|l|}{ Preferred treatment of mental disorders: } \\
\hline Biomedical & $217(79)$ \\
\hline Faith based & $50(18)$ \\
\hline Others (e.g. herbs) & $7(3)$ \\
\hline Total & $274(100)$ \\
\hline
\end{tabular}

*Biological causes are causes due to the malfunctioning of the human body especially the brain include pathophysiological factors.

\section{Forms of stigma and discrimination}

Table 3 shows the forms of stigma and discrimination associated with mental disorders at the patient level. The forms of stigma identified by respondents were economic, psychological and social. Seventy-two percent of the reported stigmas were social, ranging from family blame, ridicule and mockery (30\%) to development of "not-to-be-seen" syndrome. The economic stigma was mainly no access to food (14\%) and the psychological stigma was loss in self-esteem (13\%).

The forms of discrimination associated with mental disorders were mainly economic (46\%) and social (54\%). The economic discrimination ranges from employment related issues like job loss $(2 \%)$ to household support issues like denial of food $(10 \%)$.
The social discrimination ones were marital refusals $(10 \%)$ to "under-the-table" charges for medical treatment.

Table 3 Forms of stigma and discrimination of mental health patients

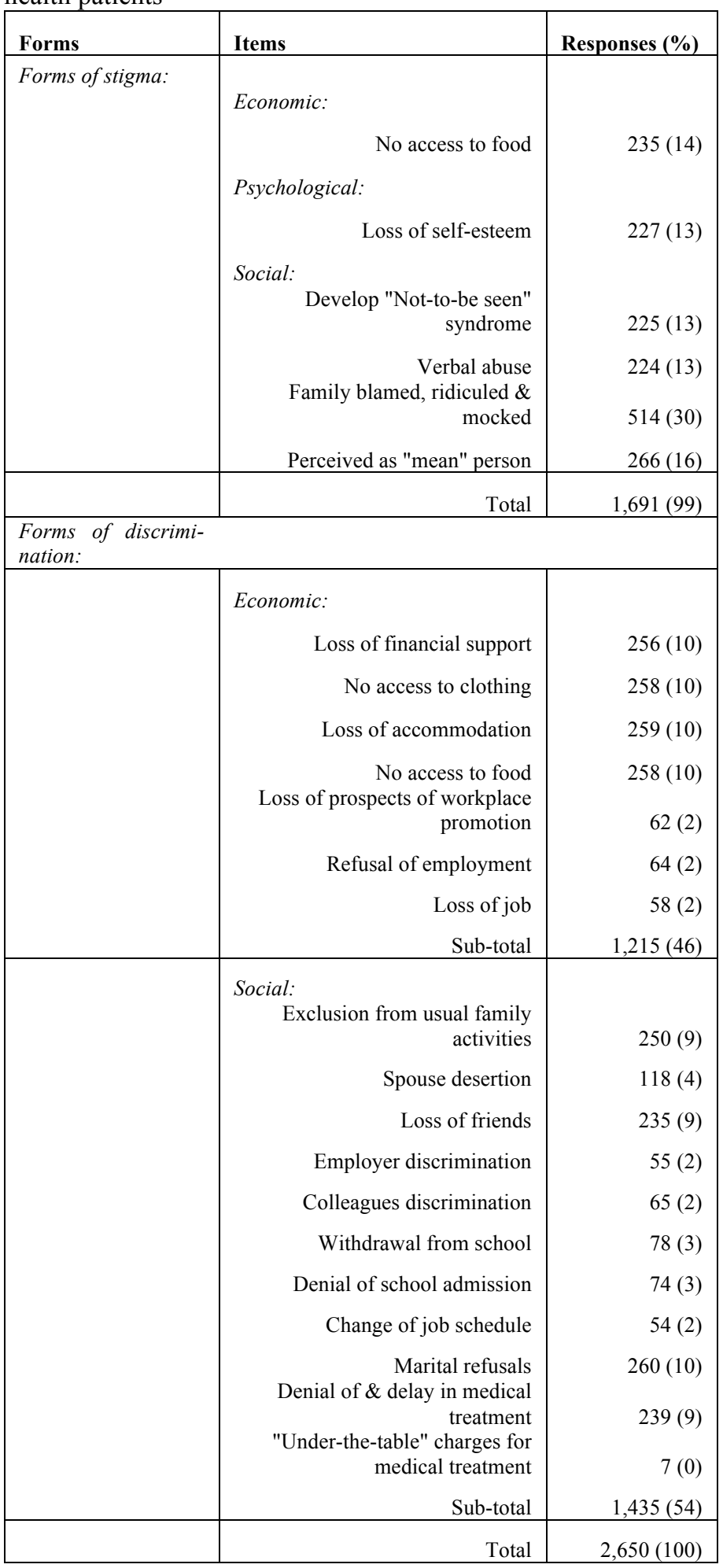




\section{Levels of stigma and discrimination}

Figure 1 show that was no significant difference stigma and discrimination of patients at all levels, namely, individual, family, work, employment, education and health. The mean score ratings shows the individual level had the highest mean of 1.8 , followed by work, employment and education (1.7), family (1.6) and health (1.3).

According to a 44 year old male, patient:

"I lost my job because I have a mental disorder, my wife left me, and the children are scattered, they sometimes come to me, I'm rejected by all except few of my family members though they too do not receive me well, they sometimes think of what I have done for them when I was wealthy and do good small to me sometimes".

A 38 years old caregiver also noted that:

"If you accept you are mad, people will shun your company, no job, no marriage, no home, so one has to deny it and when the sickness grows, they roam on the streets, beg for food and that is their end, they cannot get well again".

Another patient reported that:

"When my mother got pregnant of me, she became mad, I was called mad person's son. I could not complete my elementary education because of financial difficulties and no one was willing to help a mad woman's son in my community, everybody shun my company. Any woman I proposed to; refuses my proposal, look at me, at my age I am not married and I feel shy to sing on stage. I am a good composer and a singer; I sing well in studio but cannot perform publicly for the fear that people might not accept me since I am a mad person's son".

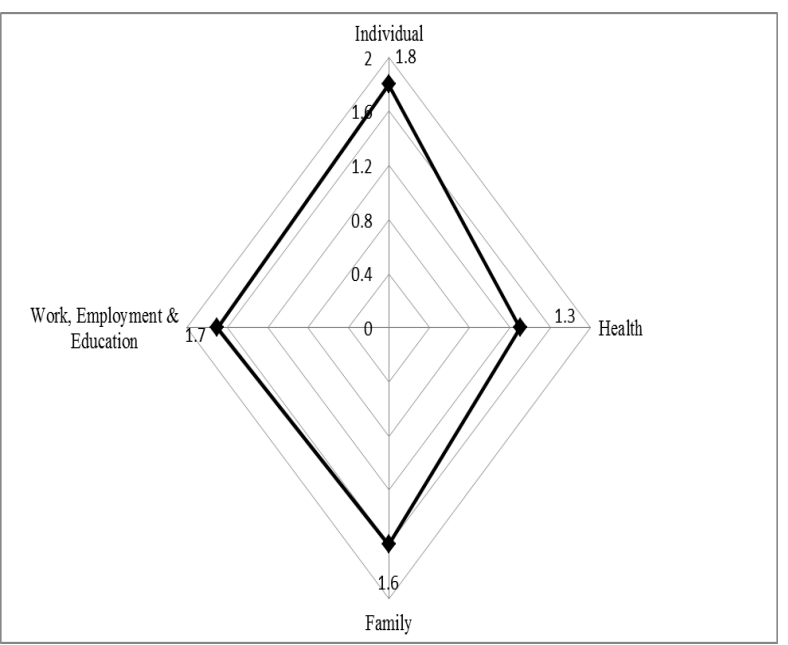

Figure 1 Mean scores for the levels of stigma and discrimination

\section{Coping strategies of the mental patients}

The most predominant strategy used by mental health patients was social $(88 \%)$. This comprises of supportive spouses and family (23\%), prayers (21\%), aggression and reaction (14\%), avoidance of marriage (13\%) and others (16\%). Economic strategies (i.e., fore go meals and animal rearing) form only $7 \%$ and psychological strategies (i.e., smoking marijuana and over sleeping) were $5 \%$.

\section{DISCUSSION}

The study indicates that about half of the patients were over 35 years old and majority was women. Most of them were not married and about third have primary education. Further responses also indicated that mental health patients and their caregivers noted that the causes of mental disorders were predominantly biological with over a third been afflicted by mental disorder between 1 to 4 years. They also preferred biomedical treatment.

The forms of stigma and discrimination were broadly economic, social and psychological. There was no significant difference in the levels of their stigma and discrimination from health, individual, family, work, employment to education. Households have also developed various social strategies to cope with their predicament.

Irrespective of sex, mental patients and their care givers experienced various forms and level of stigma and discrimination. As noted by Goffman, stigma exists when a person is identified by a label that sets the person apart and links the person to undesirable stereotypes that result in unfair treatment and discrimination. ${ }^{2}$ Additionally, others have observed that the social stigma attached to mental ill health and the discrimination mental health patients experience make their difficulties worse. ${ }^{15}$ This social form of stigma and discrimination has also been found with other diseases such as HIV/AIDS. ${ }^{16}$

More females acknowledged being stigmatized and discriminated at work, employment and education levels than males. Stigma often rears its head in the workplace. This study collaborated with Canadian Mental Health Association assertion that there are incidents of mentally ill individuals losing their jobs for having spent time in hospital. ${ }^{17}$ In other cases, employees experience a loss of credibility and a concomitant loss of responsibility. Other studies have also shown that both sexes suffered stigma and discrimination at the family level ${ }^{18,19}$ and at the health level. ${ }^{15}$ WHO also indicates that individuals may be fearful of being discriminated against if they are labelled as having a mental health problem. ${ }^{5}$ 
Given this all embarrassing stigma and discrimination, mental health patients and their caregivers usually look for means to cope with all stigma and discrimination suffered. The main coping strategy identified in this study was social $(88 \%)$. This includes developing 'notto-be-seen' syndrome, prayers, avoidance of marriage and some aggression and reaction. Similar coping behaviours have been reported in other study. ${ }^{20}$

The study recognized several limitations. First the timing or the period of the study as some of the patients and caregivers who might be experiencing stigma and discrimination might not have reported at the mental health clinic during the study period. Secondly, focus group discussions in the two communities for patients' caregivers may have influenced their responses.

Finally, this paper presents the range of the various forms and levels of stigma and discrimination in a municipality with attendant coping and support strategies. Further research is required with a large sample to explore the whole gamut of the stigma and discrimination in both rural and urban communities to inform mental health policy in the country.

\section{CONCLUSION}

Mental health patients and their families suffer from stigma and discrimination from the individual, family, work, employment, education to the health level. This ultimately leads them to shy away from treatment and rehabilitation, and adapt wrong and unsustainable coping strategies. Thus, community level policy on mental health care needs to be developed and implemented. Furthermore mental health education needs to be intensified at the community level.

\section{ACKNOWLEDGEMENT}

The authors wish to express their unconditional gratitude to all participants in this study for agreeing to share their experiences with the researchers. We are also grateful to the research assistants and anonymous individuals who independently coded the interviews.

\section{REFERENCE}

1. Health and Development Networks. Advocacy for action on stigma and HIV/AIDS in Africa. Chiang Mai. Health and Development Networks. 2001. Retrieved 16/02/2012.

2. Goffman E. Stigma: Notes on the Management of Spoiled Identity. Englewood Cliffs, NJ: Prentice Hall 1963;(1): 2-18.

3. Malcolm A. HIV-related stigmatization and discrimination: Its forms and contexts. Critical Public Health. 1998;8(4): 347-370.
4. WHO. Advocacy for Mental Health. Geneva. World Health Organisation. 2003;17- 47.

5. WHO. World Mental Health Survey Consortium: Prevention, Severity and Unmet Need for Treatment of Mental Disorder in the World. JAMA. 2004;291(21) 2581-2590.

6. WHO. The World Health Report Mental Health: New understanding, New Hopes. Geneva. World Health Organisation. JAMA. 2001;15(2) 115-120.

7. Link BJ, Mirokznik J, Cullen F. The effectiveness of stigma coping orientations: Can negative consequences of mental illness labeling be avoided?" Journal of Health and Social Behavior. 1997;32: 302-320.

8. WHO. The 'undefined and hidden' burden of mental health problems. Fact Sheet. 2008, 218. Retrieved 16/02/2012.

9. Schulze B and Anger Meyer MC. Subjective experiences of stigma. A focus group study of schizophrenic patients, their relatives and mental health professionals. Soc Sci Med. 2003; 56(2):299-312.

10. Carne B. A Consumer Perspective. Canadian Journal of Community Mental Health, Special Supplement. 1998; (3) 21-28.

11. Stolzman JD. The Distribution and Treatment of Mental disorders by Social Class: A Review of the Research and Theoretical Interpretation. Health, Illness, and Health Care Toronto: Harcourt Brace Canada; $2^{\text {nd }}$ edition:1994: 444-465.

12. Ghana News Agency, 2010. The Daily Graphic, $19^{\text {th }}$ April, $2010 ; 49$.

13. Ghana Statistical Service. Ghana Population and Housing Census Report 2010. Accra: Ghana Statistical Service. 2011.

14. Volta Regional Mental Health Report. Ghana Health Service: Volta Regional Health Directorate Annual Report. 2011.

15. Mental Health Foundation of UK. [Available at http://www.mentalhealth.org.uk/our-work. 2000; Retrieved on 29/7/2012].

16. Parker, R and Aggleton, P. HIV/AIDS-related Stigma and Discrimination: A Conceptual Framework and an Agenda for Action. [available at www.popcouncil.org/horizons/ horizons.html. 2002; Retrieved on 18/02/2012].

17. Canada Parliament Senate. Mental Health Mental Illness and Addiction; Interim 2004: The Standing Senate Committee On Social Affairs, Science And Technology: Journals of the Senate; Report $1: 2004 ; 37-62$.

18. Ostman M and Kjellin L. Stigma by association: psychological factors in relatives of people with mental illness. Br J Psychiatry. 2002 Dec;181:4948 . 
19. Corrigan PW and Watson AC. Understanding the impact of stigma on people with mental illness. World Psychiatry. 2002; 1: 16-20.

20. Keller J. Blatant stereotype threat and women's math performance: self-handicapping as a strategic means to cope with obtrusive negative performance expectations. Sex Roles. 2002; 47:193 98. $\bullet$ 